\title{
Non-Destructive Tests for the Structural Assessment of a Historical Bridge over the Tua River
}

\author{
Isabel Valente ${ }^{1, a}$, Luís F. Ramos ${ }^{1, b}$, Kevin Vasquez ${ }^{2, c}$, Paulo Guimarães ${ }^{2, d}$ \\ and Paulo B. Lourenço ${ }^{3, e}$ \\ ${ }^{1}$ Assistant Professor, ISISE, University of Minho, Department of Civil Engineering, Portugal \\ ${ }^{2}$ Former Master Student, ISISE, University of Minho, Department of Civil Engineering, Portugal \\ ${ }^{3}$ Full Professor,ISISE, University of Minho,Department of Civil Engineering, Portugal \\ aisabelv@civil.uminho.pt, bIramos@civil.uminho.pt, 'kevin.dick.vazquez@estudiant.upc.edu, \\ da48765@alunos.uminho.pt, epbl@civil.uminho.pt
}

Keywords:Dynamic analysis, modal testing, FE, mode shape, sensitivity analysis.

\begin{abstract}
Paradela Bridge is a metallic bridge located along the bank of the Tua River in northern Portugal. While the bridge is not currently in service, its structure is representative of many metallic truss structures built across the continent between the XIX and the XX century. Tua Line belongs to the Douro area that UNESCO recently declared as world heritage. This study acquires its importance since it might serve as an insight for the study of many other similar structures all over the country. This paper comprises a historic investigation of archived documents, an on-site survey to evaluate its present conditions, a dynamic testing and the construction and calibration of numerical models in finite element analysis (FEA) software, structural assessment and capacity rating estimation. The purpose of constructing numerical models was to evaluate the suitability of the bridge under the original loading and in accordance to modern design standards. The historical research revealed that the truss bridge was designed as a simply supported elementand that a series of hand calculations were carried out on individual structural elements (e.g. main trusses, stringers and floor beams). Furthermore, a dynamic test was conducted in order to identify the global dynamic properties of the structure and to calibrate numerical models that ensure reliability and representativeness. FE models served through the structural assessment of the bridge in accordance with modern design codes and to estimate the safety of the bridge. Likewise, a nonlinear failure analysis was also conducted in order to estimate the capacity rate of the bridge and the likely failure modes.
\end{abstract}

\section{Introduction}

Paradela Bridge structure is a metallic underslung deck truss railway bridge shown in Fig.1 and it is located along the Tua River in Trás-os-Montes northeast Portugal. Tua line is a narrow gauge railway line of $133.8 \mathrm{~km}$ in length intended to connect the Douro vintner region starting from Foz do Tua station and ending at Bragança station[1]. Crossing a dramatic landscape of deep valleys, it is considered as one of the most difficult railway lines ever built in the Iberian Peninsula.
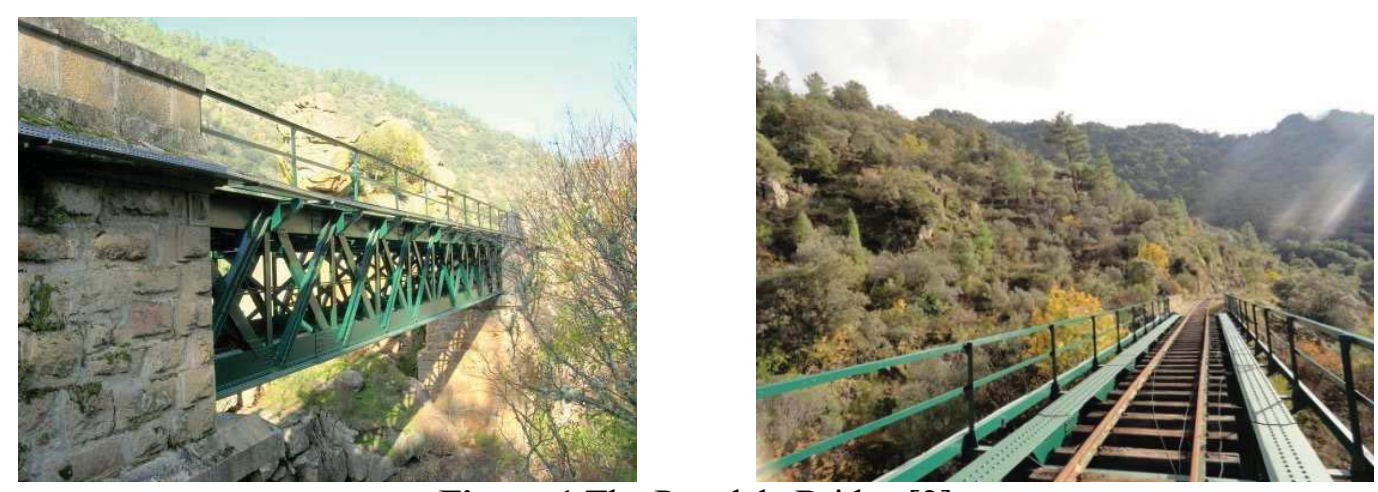

Figure 1 The Paradela Bridge [2] 
Tua line was designed in 1878 by the Portuguese engineer Antonio Pinheiro. The first section of $54 \mathrm{~km}$ (From Foz do Tua to Mirandela) was built by the National Railway Company and opened to traffic in 1887. It was possible to determine that Paradela Bridge was completed in 1886. The remaining section (From Mirandela to Bragança) was completed by 1906 and opened to service in phases for transportation and tourism. The railway line was originally intended to use steam locomotive cars which would transport load. From the 1970s onwards trains on the line were hauled by CP Class Alsthom 9020 (Kazakhstan) diesel locomotives, and finally diesel rail buses type Duro Dakovic 9300 and 9500 (Poland) to transport passengers [1].

Since Paradela Bridge is not currently in service, it was a unique opportunity to study the heritage structure. Therefore, a group of researchers found Paradela Bridge being an interesting case study to evaluate via non-destructive tests and numerical models. The studies implied visual inspection, geometric survey, dynamic tests, and others. The aim was to evaluate the current conditions of a representative structure built in the late XIX century and its likely further use.

\section{In-situ structural survey}

A visual inspection of bridge was carried out in order to verify and compare information gathered through the historical survey, i.e. the actual geometry of the bridge, the dimensions of the cross sections of each element and the used materials. This allowed a better understanding of the connections work principle, likely changes throughout the years and finally to detect likely damage or material decay.

Materials.In spite the fact that no information regarding the materials used was found in the original design documents and due to the impossibility of carrying out non-destructive or destructive tests onto the bridge, visual characterization and dating were used to define the materials of the bridge for its study. Since the construction was completed in 1886, wrought iron or early steel were the likely materials used to build the bridge [2]. The built-up section members and the presence of riveted connections corroborate the possible use of these materials. The corresponding values for the relevant mechanical properties of both materials were obtained from literature.

Fig. 2 provides a timeline of the most common materials used in the period that goes from late XVIII century to mid XX century and presents their mechanical properties, as proposed by Bussell [3]. Values for wrought iron and steel before 1906 were used to study Paradela Bridge.

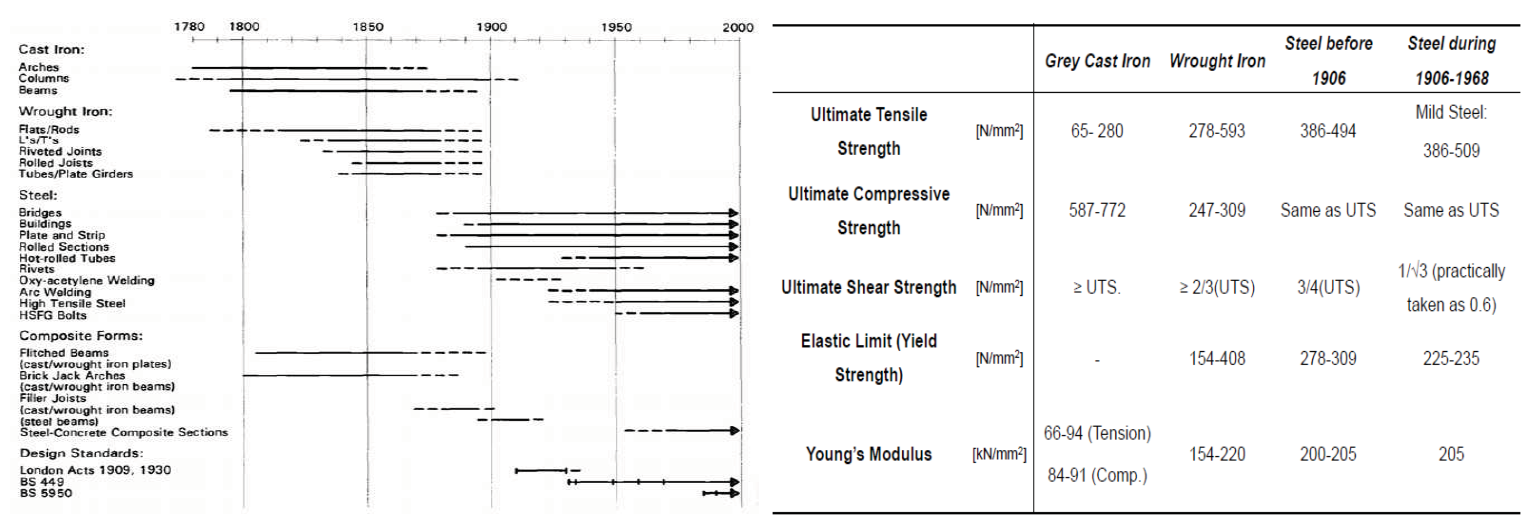

Figure 2 Dating and mechanical properties of historic metallic materials [4]

Geometry survey.The aim of the geometrical survey was to verify and compare information contained in the original documents as well as to obtain the missing information required to build a reliable and representative numerical model. Fig. 3 shows some of the photos taken during the onsite geometry survey. 

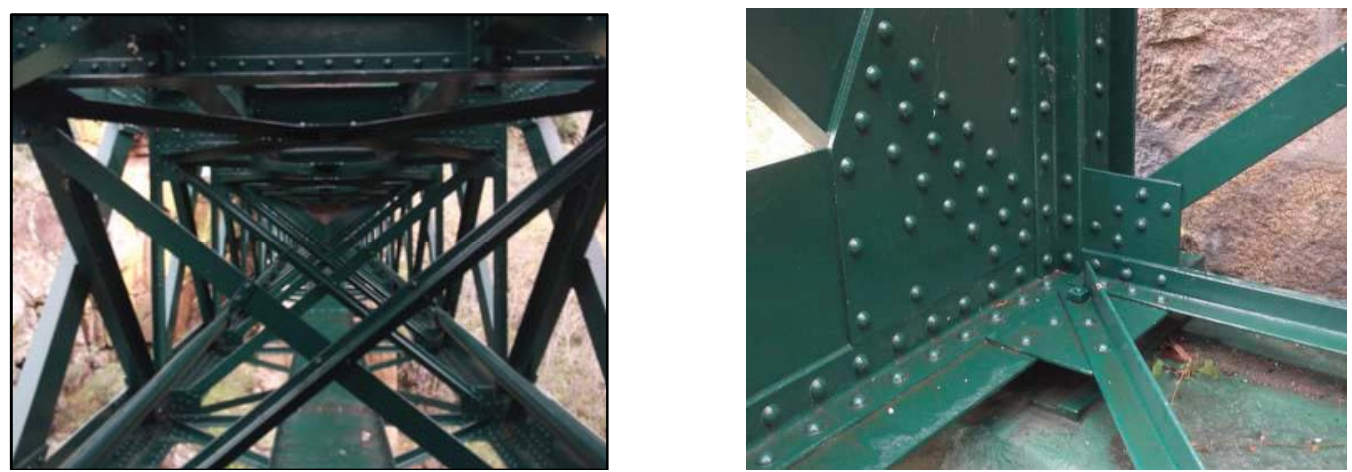

Figure 3 Images of the on-site geometry survey [2]

The dimensions of the bridge are $25.85 \mathrm{~m}$ in length and consist of 10 similar modules, each of $2.58 \mathrm{~m}$ length and $2.6 \mathrm{~m}$ width (see Fig. 4).The structure is simply supported on masonry abutments(see Fig. 1 and Fig. 4). The dimensions measured on-site were fairly similar to the information contained in the historic files with the exception of the width of the bridge that was largerthan in the drawings by $25 \mathrm{~cm}$, as the drawings show in Fig. 5. Lateral bracing systems are present in the horizontal and vertical planes. The vast majority of the members are built-up sections, and only some few bracing elements were identified as hot rolled sections. Furthermore, missing information was gathered of secondary members present, as well as smallchanges in main member's dimensions that might have been changed at some point.

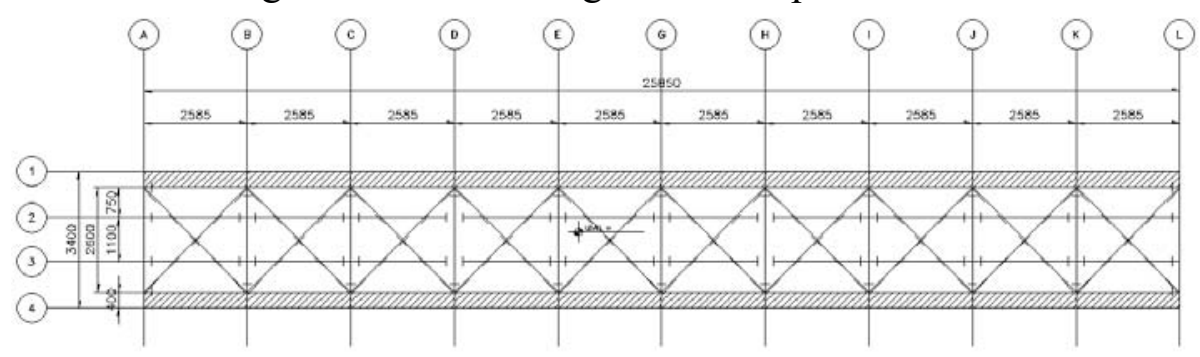

Figure 4 Plan view Paradela Bridge [2]
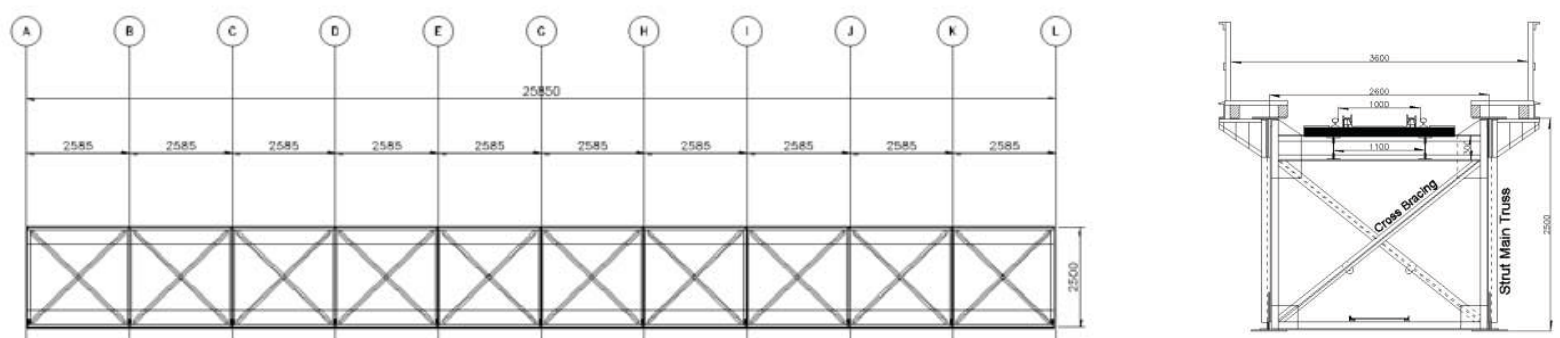

Figure 5 Elevation and cross section Paradela Bridge [2]

On the other hand, no information regarding the design of the connections was found; so, the onsite survey served to get to know their type and current condition. Gusset plates and rivets were used all over the bridge connections and no welding works were detected. Moreover, no corrosion was found at all and no missing elements were identified. In fact, the condition of the structure is good due to maintenance performed in 2007 according to tags found along the bridge. Despite no further investigations of the supports of the bridge, visual inspection suggested that the abutments are sound enough and no cracks or damage were perceived [2].

\section{Dynamic Identification Tests}

Test Procedures.In order to evaluate the dynamic properties of the Railway Bridge, vibration levels and identification of modal parameters were determined with on-site dynamic tests. Such tests consisted in acquiring the response of the structure due to the ambient or natural excitation and due to forced excitations imposed withan impact hammer [2]. 
The current abandoned state of the line created a great opportunity to perform the forced vibration test with the impact hammer and compare it with the ambient test results. In this way, a comparison of two modal analysis approaches was made, i.e. an operational modal analysis and the traditional modal analysis using the data from both input and output.

In order to ensure a good spatial distribution along the structure for the dynamic test, a regular grid of 22 points was chosen. This arrangement ensured covering the entire top plane of the structure while making it coincident to the nodes of the top chord of trusses, in both vertical and lateral directions as Fig. 6 shows, so, as to ensure that no local behaviour would affect the results.

Top View

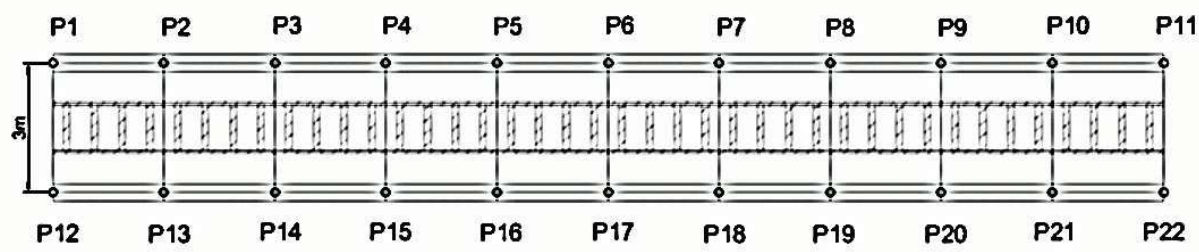

Figure 6 Measurement points scheme [2]

Test Results.Fig. 7 presents the average normalized spectral density functions from the transversal and vertical recordings, respectively[4]. Firstly, the signals were decimated from $50 \mathrm{~Hz}$ to $200 \mathrm{~Hz}$, and then the cross power density function was estimated using Welch's averaged modified periodogram method [5] and dividing the signal in segments of 2048 points with $50 \%$ overlap. A Hanning window was used for each segment to avoid distortion such as spectral leakage.
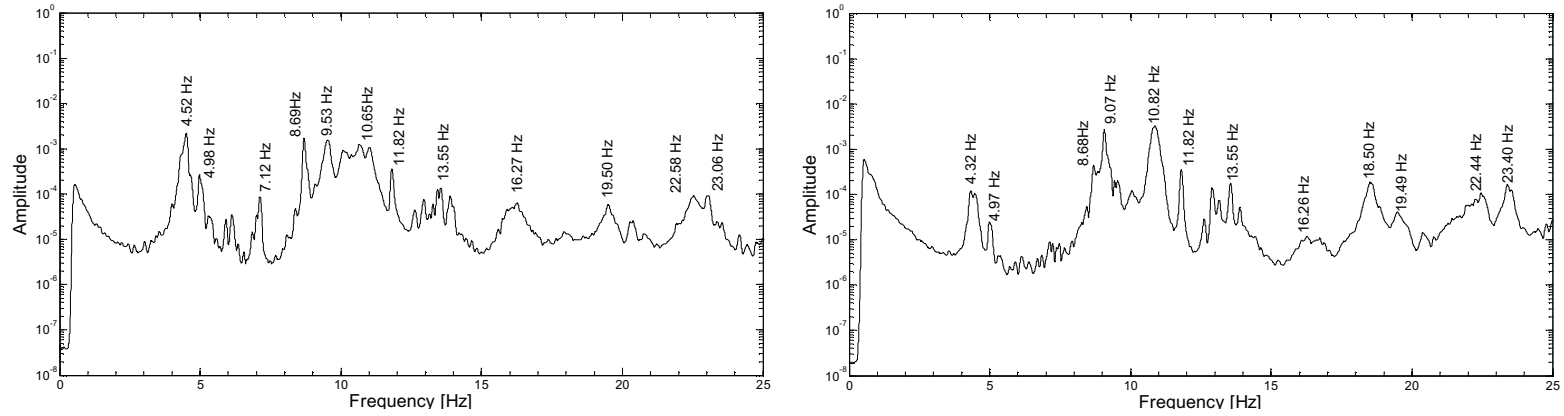

(a)
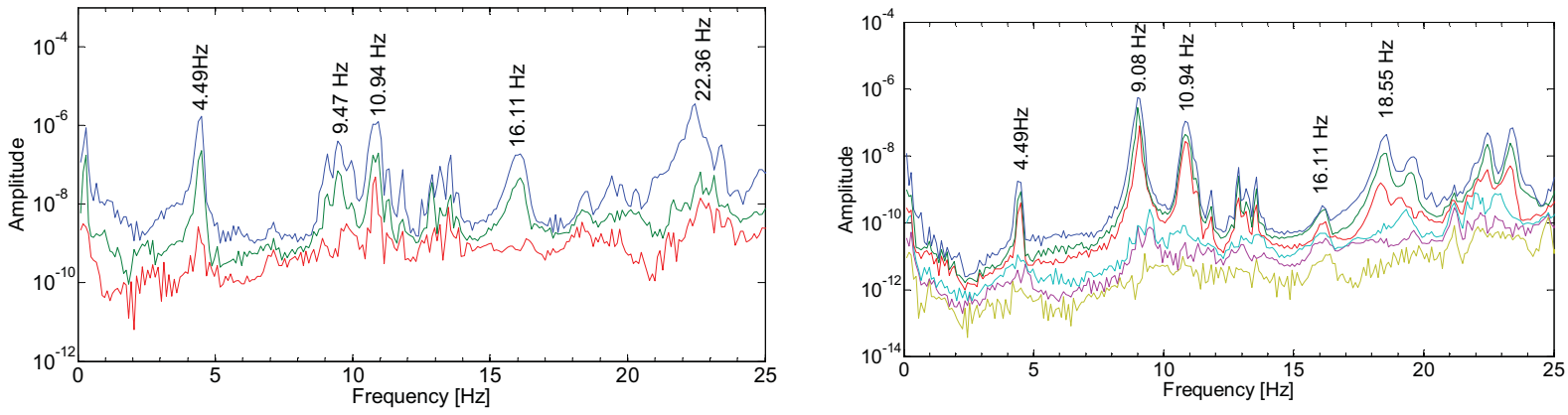

(b)

Figure 7 Results from the dynamic identification tests: (a) Average normalized spectral density from horizontal (Left) and vertical recordings (Right); and (b) Complex Modal Indicator Functions for the horizontal (Left) and vertical recordings (Right).

The results for forced vibration test with the impact hammer were very similar in terms of vertical resonant frequencies and mode shapes. Since the impacts were given in vertical to the bridge some lateral accelerometers were missed, thus lateral mode shapes were not easily identified from the forced vibration test recordings. Nevertheless, the comparison between such different techniques are good to realize that operational modal analysis techniques that use lower and stochastic vibration methods [6-9] can achieved very good results.

Fig. 8 shows the first five mode shapes and damping coefficients obtained by ambient vibrations. The frequencies range from 4.46 to $16.25 \mathrm{~Hz}$ and an average damping $1.15 \%$ can be observed. 


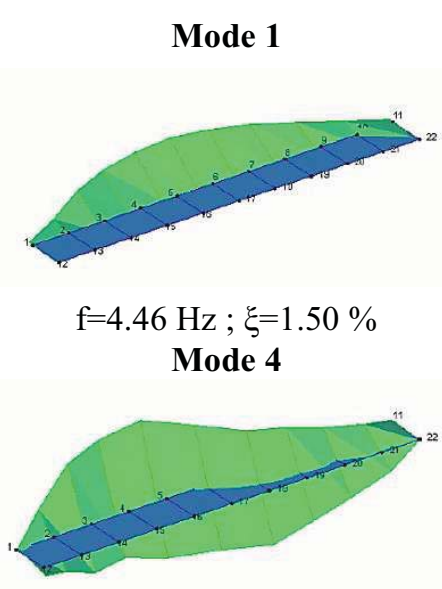

$\mathrm{f}=10.77 \mathrm{~Hz} ; \xi=1.18 \%$

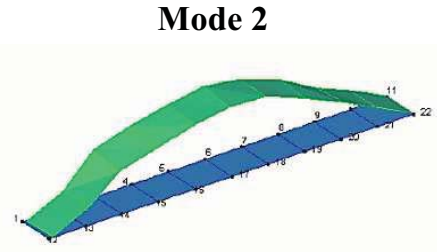

$\mathrm{f}=9.03 \mathrm{~Hz} ; \xi=0.79 \%$

Mode 5

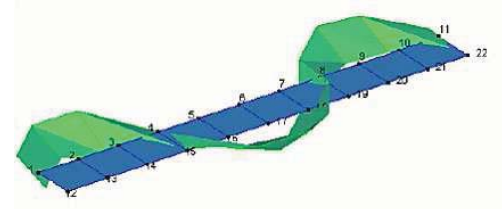

$\mathrm{f}=16.25 \mathrm{~Hz} ; \xi=1.54 \%$
Mode 3

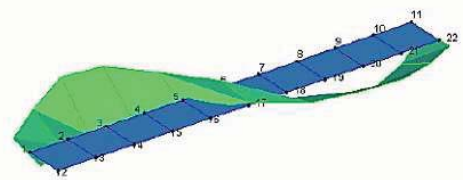

$\mathrm{f}=9.51 \mathrm{~Hz} ; \xi=0.74 \%$

Figure 8 First mode shapes and damping coefficients.

\section{Calibration of Numerical models}

In order to evaluate the global response of the bridge under the likely loads acting on it, two mathematical models were built. The first model was built in the commercial software SAP2000 [10] based on Finite Element Analysis (FEA) and the second model was constructed in DIANA [11] software, also based on FEA, see Fig. 9. The aim of having two models was firstly to verify experimental results and then to perform several other different analyses to assess the structural integrity of the structure. Bearing in mind that a numerical model can never truly represent the actual behaviour of a structure; the ability to compare their modal properties with experimental results enabled the validation of models that afterwards served for the structural assessment of the bridge through further analyses.Table 1 contains the values obtained by the two FEM models constructed to evaluate the dynamic properties of Paradela Bridge.

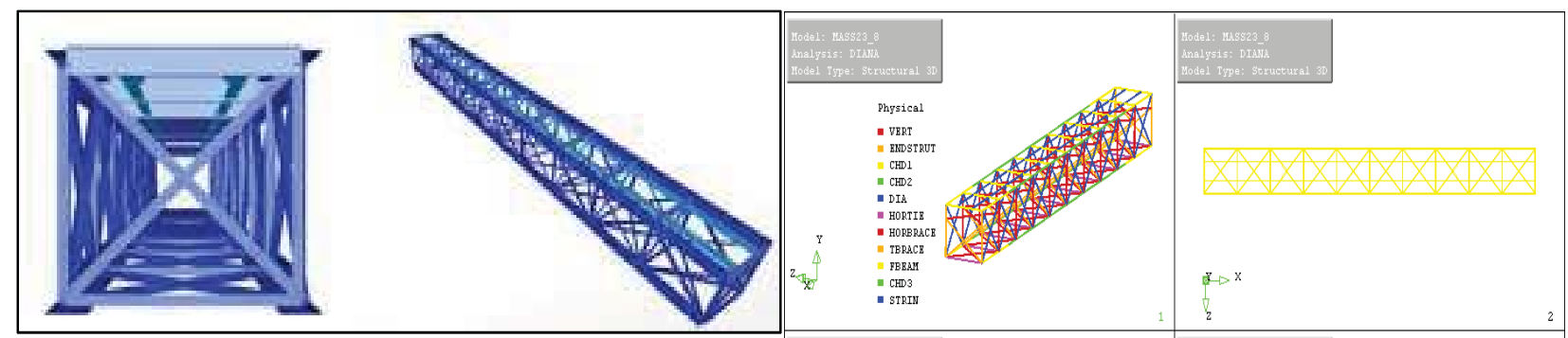

Figure 9 Two numerical models for the bridge, SAP200 (Left) and DIANA (Right).

Table 1 Comparison of DIANA versus SAP2000 results [2].

\begin{tabular}{ccc|cc|cccr}
\hline Mode & $\begin{array}{c}\text { Experimental } \\
\text { Frequency } \\
{[\mathrm{Hz}]}\end{array}$ & Modeshape & $\begin{array}{c}\text { Frequency } \\
{[\mathrm{Hz}]}\end{array}$ & Modeshape & $\begin{array}{c}\text { Srequency } \\
{[\mathrm{Hz}]}\end{array}$ & Modeshape & $\begin{array}{c}\text { Error } \\
{[\%]}\end{array}$ & MAC \\
\hline 1 & 4.46 & $1^{\text {st }}$ Lateral & 4.81 & $1^{\text {st }}$ Lateral & 4.57 & $1^{\text {st }}$ Lateral & 5.00 & 0.94 \\
2 & 9.03 & $1^{\text {st }}$ Vertical & 8.63 & $1^{\text {st }}$ Vertical & 8.57 & $1^{\text {st }}$ Vertical & 0.70 & 1.00 \\
3 & 9.51 & $2^{\text {nd }}$ Lateral & 10.21 & $2^{\text {nd }}$ Lateral & 9.16 & $2^{\text {nd }}$ Lateral & 10.30 & 0.96 \\
4 & 10.77 & $1^{\text {st }}$ Torsion & 13.20 & $1^{\text {st }}$ Torsion & 11.77 & $1^{\text {st }}$ Torsion & 10.80 & 0.95 \\
5 & 16.25 & $3^{\text {rd }}$ Lateral & 15.27 & $3^{\text {rd }}$ Lateral & 12.45 & $3^{\text {rd }}$ Lateral & 18.50 & 0.97 \\
\hline
\end{tabular}

As shown in Fig. 8 and in Table 1, mode shapes and mode frequencies are not the same in both models and in results obtained from the experimental test. However, Modal Assurance Criteria (MAC) values for modes 3 and 5 show no correlation when compared with experimental results. Nevertheless, the same mode shapes of numerical models possess well correlated MAC values 
when compared to each other. Seemingly, the models are accurately predicting those mode shapes. Thus, limitations in the number of degrees of freedom (DOF) measurements during the experimental test and data acquisition are believed responsible for the difference found between numerical and experimental results. However, for the main purposes of the work, results ensure the representativeness of the numerical models and more advanced analysis can be performed.

\section{Structural assessment of Paradela Bridge}

The objective of this phase was to evaluate the capacity of Paradela Bridge to sustain all the loads and actions established in modern codes of design such as the Eurocode [12-13]. This analysis was performed to figure out ifthe bridge could be reopened to service in the near future, by using modern locomotive trains. The results of the analyses would let us know what parts or elements of the bridge would need to be strengthened. Therefore, two main analyses were performed: structural assessment according to Eurocodeusing SAP2000 and strength capacity rating witha nonlinear analysis performed in DIANA.

Structural Assessment by Eurocode. In order to evaluate the structural capacity of Paradela Bridge, the recommendations from the current version of the Eurocode were followed. Eurocode trainload 71 was placed along the stringers in two separate locations: with the train at mid-span and with train and extreme end of the bridge. The combination of loads established to analyse the bridge were based on the dispositionsofEN 1991-2 [15].

The post processor of SAP2000 in combination with hand calculations were used to carry out the structural revision of the elements of the bridge. In a nutshell, the results showed that several members were not able to sustain the loads suggested by the Eurocode. Actually, the analysis showed that the bridge is just able to sustain loads that are equivalent to $60 \%$ of the ones currently recommended by Eurocode.

Capacity rating of Paradela Bridge.It is clear that Paradela Bridge has successfully met the requirements that it was intended for, bystanding up and serving for more than 100 years. A capacity rating assessment would let us evaluatethe ultimate capacity of the structure by obtaining the number of times that the original loading on the bridge could be sustained. Moreover, the analysis would allow us to identifythe structural elements that would fail first and the collapse mechanism. Therefore, a nonlinear analysis was conducted using DIANA [11] software.

In nonlinear FEM, the relation between a force vector and a displacement vector is no longer linear. The analysis considers material strength past its elastic stage and into the plastic range. Considering such nonlinear properties is useful in a failure analysis because the true strength of thematerial can be considered until complete failure. In the case of Paradela Bridge, the nonlinear part of the steel stress-strain curve is now consideredandcontributes to the behaviour of the structure.

In order to determine the state of equilibrium, DIANA [11] uses an iterative searching algorithm, known as an incremental-iterative solution procedure. For the analysis, the Newton-Raphson iteration method was chosen, where the stiffness remains constant, whereas in the Regular NewtonRaphson method, the stiffness is re-calculated at each iteration. The line search method was also selected to increase the convergence rate, with an error tolerance criteriaof $10^{-8}$ to be met before a solution is found, ina maximum of 100 iterations.

A material nonlinearity analysis was first conducted, where the steel had a yield stress of $225 \mathrm{MPa}$ with a perfect plasticity model. Perfectly plastic material models assume linear forcedisplacement behaviour with a maximum strength at the yield strength that remains constant until failure. The analysis showed that the structure was able to sustain loads 3.25 times the train load with a maximum displacement of 6 centimetres at the mid span stringers (1/500 of span length), occurring at the floor beam-stringer joint on the far ends of the bridge as shown in Fig.10. 

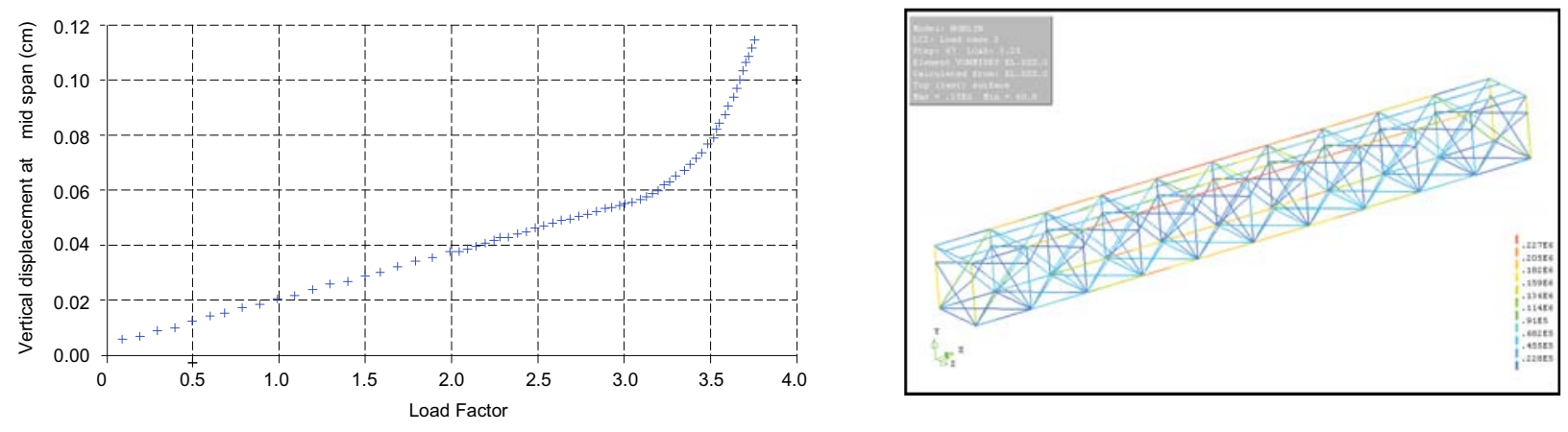

Figure 10 Nonlinear material analysis Paradela Bridge [2]

This analysis did not consider geometrical effect due to large displacements, ignoring such effects as buckling of the slender members. Ignoring geometric factors can lead to inaccuracies in cases with large displacements, stresses, or rotations. Therefore, a nonlinear analysis which would consider material as well as geometric nonlinearity had to be conducted.

Geometric effects were next considered for the same model with the identical load step command. The updated Lagrange analysis for geometric effects was selected along with material nonlinearity for this analysis. The Updated Lagrange analysis uses an updated geometry to solve the constitutive equations. In DIANA [11], the last known equilibrium state (the state at the end of the previous step) is used for the following increment. This method should represent large displacements and strains more accurately.

This second analysis resulted in a maximum deflection similar to the previous model $(6 \mathrm{~cm}$ at mid span stringer) but at a lower load factor of about 2.95 times the size of the original load intended for Paradela Bridge. In this model,convergence was much more difficult to attain and load steps had to be reduced to 0.005 in order to attain results past step 2.95 to confirm failure state.
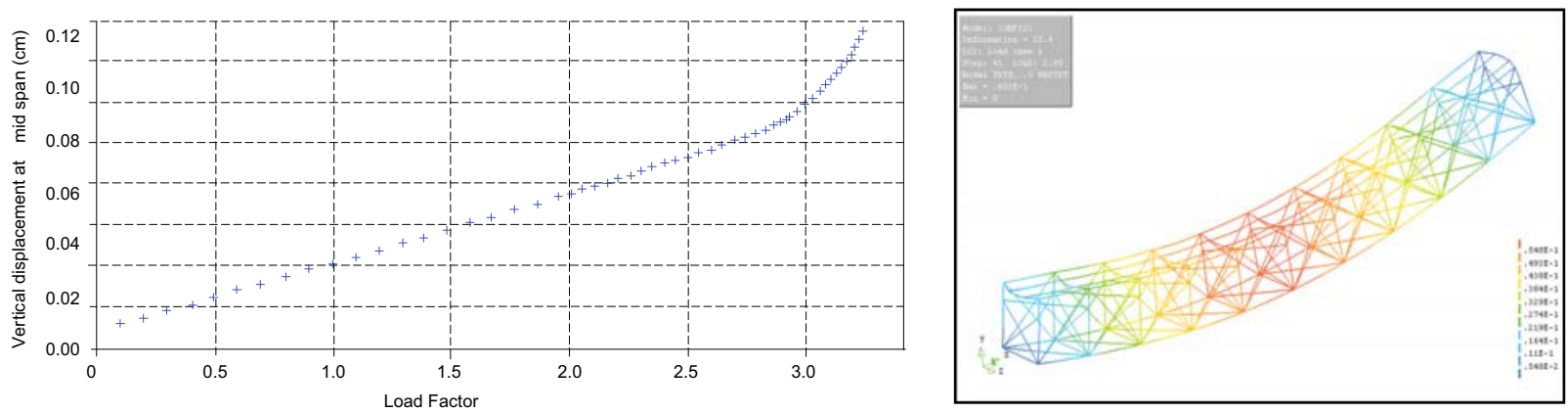

Figure 11 Nonlinear material and geometric analysis Paradela Bridge [2]

\section{Conclusions}

The aim of this paper was to describe theanalyses conducted in order to better understand the behaviour of Paradela Bridge. The truss bridge has performed well for over 120 years with no record or evidence of strengthening, yet it fails ultimate limit states per modern Eurocodes.

Dynamic identification tests were successfully conducted and the limitations and setbacks of the procedures were presented. However, the results obtained helped to validate numerical models built in FE method softwares.

Throughout a structural assessment according to Eurocode, it has been estimated that the bridge possesses a current capacity to sustain roughly $60 \%$ of Eurocode trainload 71 . Likewise, the analysis showed that at the time of its design, several forces and dynamic effects were not accounted for. A strengthening intervention was envisaged but not included in the scope of this paper.

Regarding the capacity rating of Paradela Bridge a failure analysis was performed. The results showed that Paradela has a safety factor within the range of 2.5-3.0. This value disregards lateral loads such as wind and earthquake but is an assessment of the capacity under vertical loads. 
Both numerical models showed high stresses in the floor beams and end struts under non-factored live loading, and limit state loading. Bending in the floor beams supporting the railway approach or far surpass yield in nearly every combination and configuration of loading. Buckling in some of the end strut elements has been identified as a possible concern.

The simplicity of Paradela Bridge combined with its current unused state represented an opportunity to understand the behaviours of a structural form that was common to bridge engineering in late XIX century and early XX century. Many examples still exist today, meaning that understanding the structure's performance under a variety of loads can be useful in the assessment and retrofitting of old metallic bridges.

\section{Acknowledgements}

The authors would like to acknowledge the Fundação para a Ciência e Tecnologia, which supported this research work as a part of the Project "Improved and innovative techniques for the diagnosis and monitoring of historical masonry", PTDC/ECM/104045/2008.

Special acknowledgements deserve the SAHC students that carried out the comprehensive study of Paradela Bridge while developing their integrated project for SA7 module.

\section{References}

[1] Lopes, L., Pontes e linha do Tua: História, construção e valorização. University of Minho (2011) [2]Belardi, R.; Cheong, F.; Milia, X.; Vazquez, K; Taravat, H., Structural Assessment of the Railway Bridge Paradela, Guimarães, Portugal, 2012

[3] Bussell, M., “Appraisal of Existing Iron and Steel Structures", Steel Construction Institute, Ascot, UK(1997)

[4] Guimarães, P., Ensaios de vibração para determinação dos parâmetros dinâmicos de estruturas. University of Minho (2012)

[5] Welch, P., The use of fast Fourier transform for the estimation of power spectra: A method based on time averaging over short, modified periodograms(1967)

[6] Overschee, P.V. and Moor, B.D., Subspace identification for linear systems: theory, implementation, applications, 1996 Kluwer Academic Publishers (1996)

[7] Brincker, R.; Andersen, P., Understanding stochastic subspace identification. 24th International Modal Analysis Conference(2006)

[8] Allemang, R.; Brown, D., A complete review of the complex mode indicator function (CMIF) with applications. International Conference on Noise and Vibration Engineering Katholieke Universiteit Leuven (2006)

[9] Bishop, R.E.D.; Gladwell, G.M.L., An investigation into the theory of resonance testing The Royal Society (1963)

[10] SAP2000,Release 15, Computers and Structures, Inc. (2012)

[11] DIANA, Release 9.4, TNO Delft, Netherland (2012)

[12] European Standard. Eurocode 1: Part 1: Actions on structures, European Committee for Standardisation (2002)

[13] European Standard. Eurocode 1: Part 2: Traffic loads on bridges. Brussels, European Committee for Standardisation (2002) 